\title{
Fe-Sn Intermetallic Compound Synthesized via Mechanical Alloying and Liquid Phase Sintering
}

\author{
Nattaya Tosangthum ${ }^{1}$, Pinya Meesa-Ard ${ }^{2}$ and Ruangdaj Tongsri ${ }^{1 *}$ \\ ${ }^{1}$ Powder Metallurgy Research and Development Unit, Thailand National Metal \\ and Materials Technology Center, Pathum Thani 12120, Thailand \\ ${ }^{2}$ Department of Mechanical Engineering, Faculty of Engineering, King Mongkut's \\ University of Technology Thonburi, Bangkok 10140, Thailand \\ *Corresponding author.E-mail: ruangdt@mtec.or.th
}

https://doi.org/10.12982/CMUJNS.2017.0019

\begin{abstract}
This investigation aimed to synthesize an iron (Fe)-tin (Sn) intermetallic compound ( $\mathrm{FeSn}_{2}$ ) by using a two-step process of mechanical alloying (MA) and liquid phase sintering (LPS). We demonstrated experimentally that this process was able to produce the FeSn, intermetallic compound. Two different mechanical alloying procedures for producing mechanically alloyed Fe-Sn powders were explored. In the first, mixtures of as-recieved Fe and Sn powders were mechanically alloyed. In the second, the as-received Fe powder was pre-milled first and the as-received Sn powder was then added and mechanically alloyed. Under the same liquid phase sintering conditions, the sintered materials produced via the first mechanical alloying procedure showed that the FeSn $\mathrm{F}_{2}$ content increased with increasing sintering time and left small traces of unreacted Fe and Sn materials. In the sintered materials produced via the second mechanical alloying procedure, only the FeSn ${ }_{2}$ phase was observed for all sintering times. The two-step process using the second mechanical alloying procedure performed better; it synthesized more of the FeSn $n_{2}$ intermetallic compound.
\end{abstract}

Keywords: Powder metallurgy, Mechanical alloying, Liquid phase sintering, FeSn intermetallic compounds

\section{INTRODUCTION}

Transition metal (TM)-tin ( $\mathrm{Sn}$ ) based intermetallic compounds are new active materials used as energy storage components for electrochemical anode structures, due to their delivered capacity and cycling stability. Energy storage devices, or batteries, especially rechargeable lithium-ion batteries (LIBs), are important power sources for various commodities such as portable electronic devices, plug-in hybrid electric vehicles, and all-electric vehicles (Chen, 2013). In addition, intermetallic compounds, such as $\mathrm{Sn}-\mathrm{Ni}$ alloys, $\mathrm{Sn}-\mathrm{Co}$ alloys, $\mathrm{Sn}-\mathrm{Cu}$ alloys, and Sn-Fe alloys, are employed to solve the volume expansion problem 
during discharge/charge (Zhang et al., 2008). In the development of high-performance, lithium ion battery, anode structures (Paul et al., 2005; Richter and Eberhard, 2005), $\mathrm{FeSn}_{2}$ has been shown to have the best composition among the Fe-Sn intermetallic compounds (Naille et al., 2007; Chamas et al., 2011; Wang et al., 2011). The cycling performance of the $\mathrm{FeSn}_{2}$ intermetallic compound is constant over 50 cycles at a specific capacity higher than $400 \mathrm{mAhg}^{-1}$; the specific capacity is higher for a $\mathrm{FeSn}_{2}$ /graphene composite electrode, exhibiting a higher capacity than the conventional carbonaceous anode $\left(372 \mathrm{mAhg}^{-1}\right)$ (Mao and Dahn, 1999; Lee et al., 2010).

This investigation aimed to synthesize iron (Fe)-tin ( $\mathrm{Sn}$ ) intermetallic compound $\left(\mathrm{FeSn}_{2}\right)$ by using a two-step process consisting of mechanical alloying (MA) and liquid phase sintering (LPS). Mechanical alloying is a simple and low-cost process (Koch and Whittenberger, 1996; Hubertus and Malcolm, 2006). Thus, this quick mechanical alloying is employed only for producing fine particulate materials with good interfacial contact between the two elemental powder particles. Intermetallic compound formation during the mechanical alloying step is kept to a minimum so that the mechanically alloyed powders could be further formed into desired shapes by a subsequent, conventional, metal-forming process. More recently, a two-step process based on mechanical alloying and sintering has been employed to synthesize different alloys and intermetallic compounds, including $\mathrm{CoSn}_{2}$ (Naille et al., 2007), $\mathrm{MnSn}_{2}$ (Mahmoud et al., 2013), and anomalous NiSn eutectic (Tongsri and Tosangthum, 2011).

This research tested two different mechanical alloying processes, as part of the two-step process, to produce mechanically alloyed Fe-Sn powder. In the first procedure, conventional mechanical alloying was employed, i.e., mixtures of as-recieved $\mathrm{Fe}$ and $\mathrm{Sn}$ powders were mechanically alloyed for $25 \mathrm{~h}$. In the second procedure, the as-received Fe powder was pre-mechanically alloyed for $50 \mathrm{~h}$ and the as-received Sn powder was then added and mechanically alloyed for $25 \mathrm{~h}$. The mechanically alloyed powder compacts were then processed via liquid phase sintering at at $600^{\circ} \mathrm{C}$ for different time periods.

\section{MATERIALS AND METHODS}

The raw materials were elemental iron $(\mathrm{Fe})$ and tin $(\mathrm{Sn})$ powders. The pure Fe (99.99 wt \%) powder (mean diameter of $180 \mu \mathrm{m})$ was obtained from Hoganas, Sweden. The pure Sn (99.99 wt \%) powder (mean diameter of $75 \mu \mathrm{m})$ was produced by gas atomization. The Sn powder was produced according to Morakotjinda et al. (2010). The elemental powder mixtures of Fe and $\mathrm{Sn}$ were prepared according to the atomic mass ratio of $\mathrm{FeSn}_{2} ; 19 \mathrm{wt} \%$ of $\mathrm{Fe}$ and $81 \mathrm{wt} \%$ of Sn. Two different mechanical alloying procedures for producing mechanically alloyed Fe-Sn powder were employed. In the first, mixtures of as-received Fe and $\mathrm{Sn}$ powders were mechanically alloyed for $25 \mathrm{~h}$. In the second, the as-received Fe powder was pre-milled for $50 \mathrm{~h}$ and the as-received $\mathrm{Sn}$ powder was then added and mechanically alloyed for $25 \mathrm{~h}$. The mechanical alloying conditions employed a ball (stainless steel 316) to powder ratio of 5:1 at a milling speed of $300 \mathrm{rpm}$. 
The mechanically alloyed powders produced by the two different mechanical alloying procedures were then compacted into coin- and cube-shaped green specimens, which were sintered via liquid phase sintering at $600^{\circ} \mathrm{C}$ in a furnace under $\mathrm{H}_{2}$ atmosphere for $10,20,30,40$, and $50 \mathrm{~min}$. The phase identification of mechanical alloyed powders was conducted by X-ray diffraction (XRD). The microstructures of the mechanically alloyed powder and the synthesized intermetallic compound were observed by scanning electron microscopy (SEM). Chemical analysis was conducted using energy dispersive spectroscopy (EDS) line scanning.

\section{RESULTS}

SEM images of the mechanically alloyed Fe-Sn powders are shown in Figure 1. The microstructures of mechanically alloyed Fe-Sn powder produced by the first mechanical alloying procedure were irregularly shaped (Figure 1a) and bimetallic couple particles (Fig. 1b). A sharp interface between Fe and Sn phases was easily observed. The backscattered electron (BSE) image (Figure 1b) showed some small fragments of Fe powder particles embedded in the mechanically alloyed Sn particles without intermetallic compound formation. Again, the sharp interface between $\mathrm{Fe}$ and $\mathrm{Sn}$ phases was observed in the case of small $\mathrm{Fe}$ fragments embedded in Sn powder. The sharp interface (clear contrast along the contact line between grey Fe and white Sn particles, as shown in Fig. 1b) indicated that atomic diffusion across the interface did not occur. No diffusion across the interface was strongly confirmed by the XRD patterns, as shown in Figure 2a. The XRD pattern showed only the characteristic peaks of Fe and Sn phases. No peaks corresponding to the Fe-Sn intermetallic compounds were observed.

The mechanically alloyed $\mathrm{Fe}-\mathrm{Sn}$ powder produced by the second mechanical alloying procedure showed finer-sized (mean diameter of less than $20 \mu \mathrm{m}$, unless they agglomerated), irregular, powder particles (Figures 1c and 1d). Bimetallic couples could be observed only in the form of fine Fe fragments embedded in small Sn powder particle (Figure 1d). Sharp Fe/Sn interfaces were difficult to observe, for instance in large mechanically alloyed Fe-Sn powder particles (arrowed in Figure 1d), due to the fine sizes of the Fe particles. The experimental result indicated that the pre-milled Fe powder promoted mixing between $\mathrm{Fe}$ and $\mathrm{Sn}$ powders at both micro- and nano-scales. The mechanically alloyed Fe-Sn powder produced by the second mechanical alloying procedure showed XRD patterns of $\mathrm{Fe}, \mathrm{Sn}$, and $\mathrm{FeSn}_{2}$ phases (Figure 2b). The parameters, including the sharp interface, the bimetallic couple size, and the formation of an intermetallic compound or a new alloy are indicators for determining the powder mixing efficiency. Comparing the first (Figure 1b) and second (Figure 1d) mechanical alloying procedures suggested that the Fe powder particle size was important for the mixing process during mechanical alloying, i.e., the finer powder particle size of the pre-milled $(\mathrm{Fe})$ powder more efficiently mixed with Sn powder. 


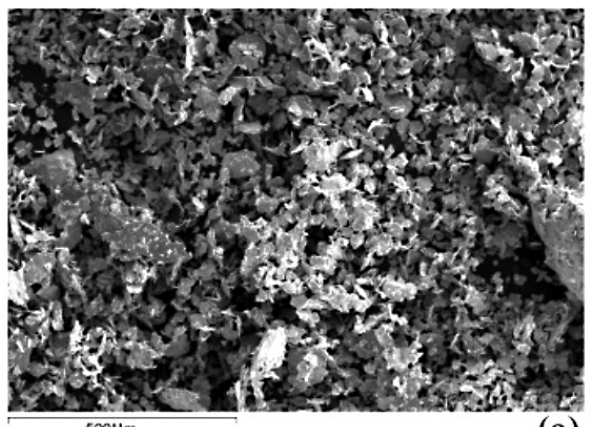

$500 \mu \mathrm{m}$

(a)

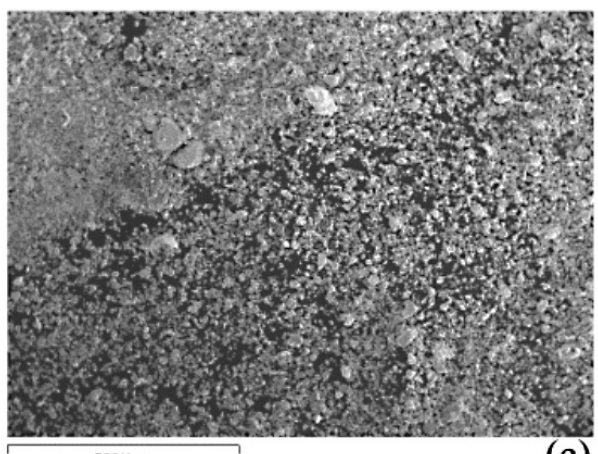

$500 \mu \mathrm{m}$

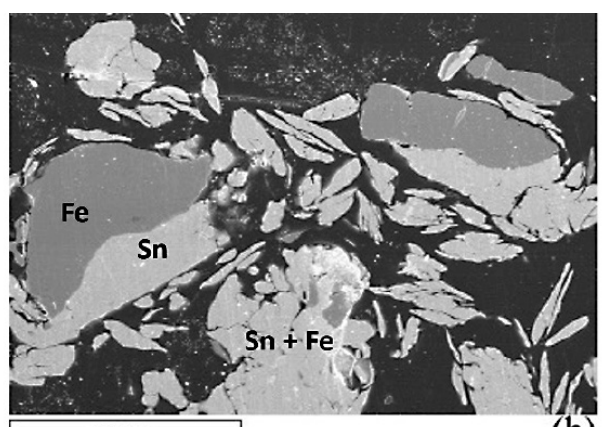

$100 \mu \mathrm{m}$ (b)

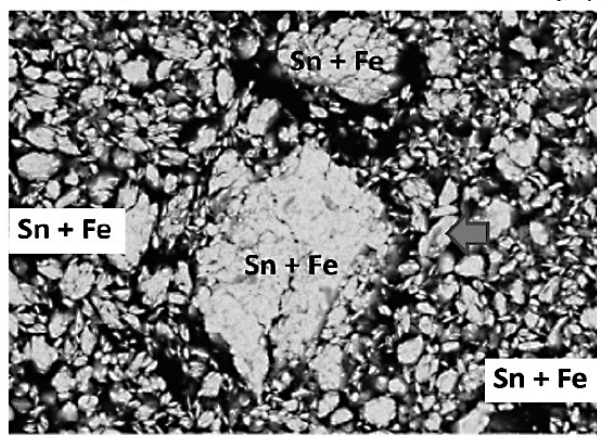

(d)

Figure 1. (a) SEM image (100x) and (b) BSE image (500x) of the mechanically alloyed $\mathrm{Fe}-\mathrm{Sn}$ powder produced by the first procedure; (c) SEM image (100x) and (d) BSE image (500x) of the mechanically alloyed Fe-Sn powder produced by the second procedure.

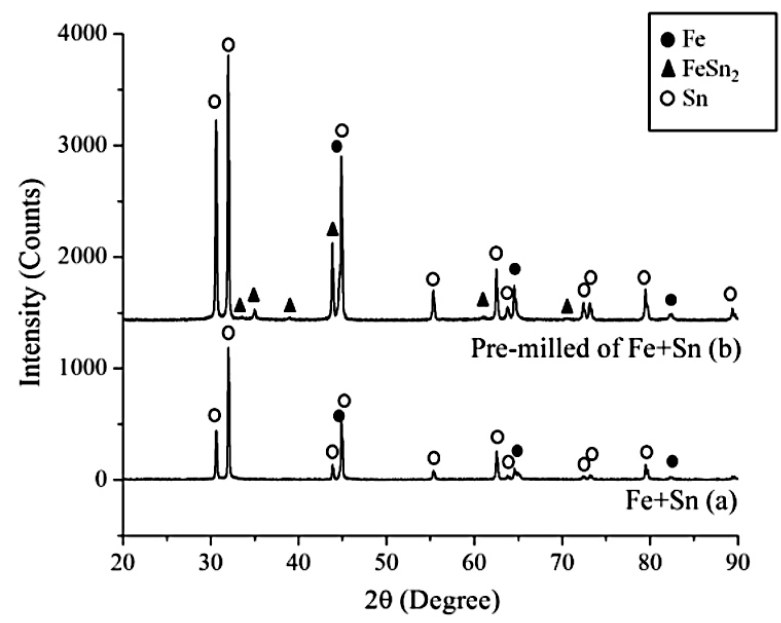

Figure 2. XRD patterns of the (a) Fe-Sn mechanically alloyed powders and (b) Fe (pre-milled)-Sn mechanically alloyed powders. 


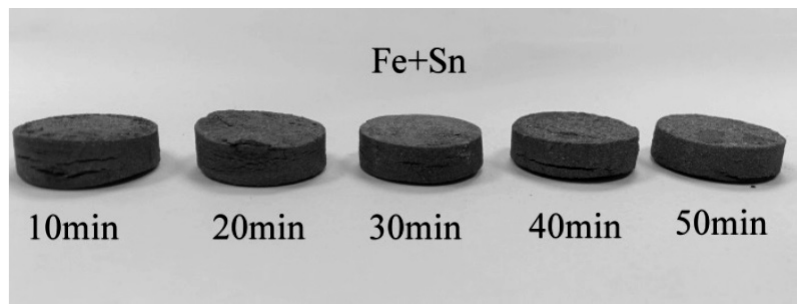

(a) Cracks decreased with increasing sintering time.

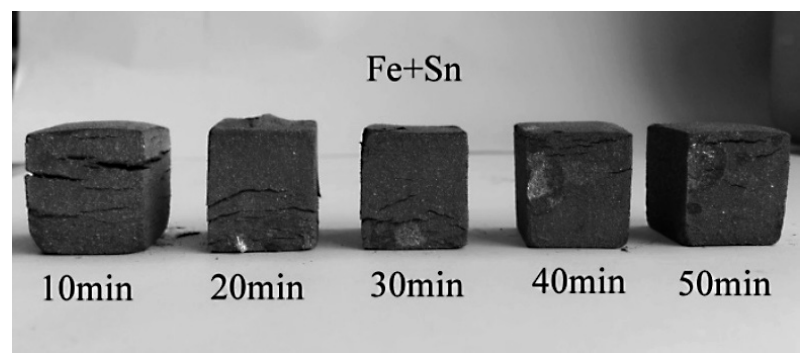

(b) Cracks decreased with increasing sintering time.

Figure 3. Sintered specimens of mechanically alloyed Fe-Sn powder compacts produced via the first procedure.

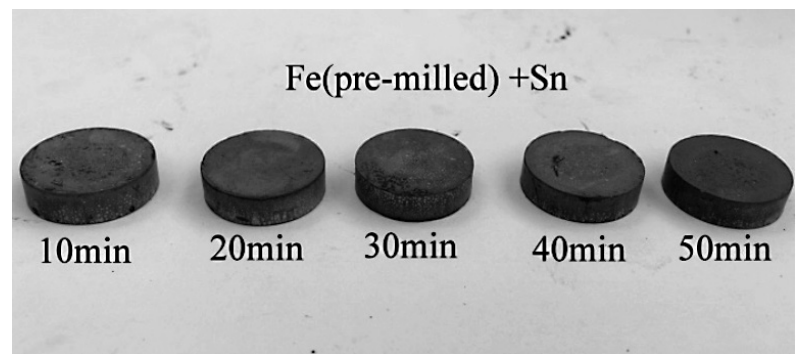

(a) No cracks

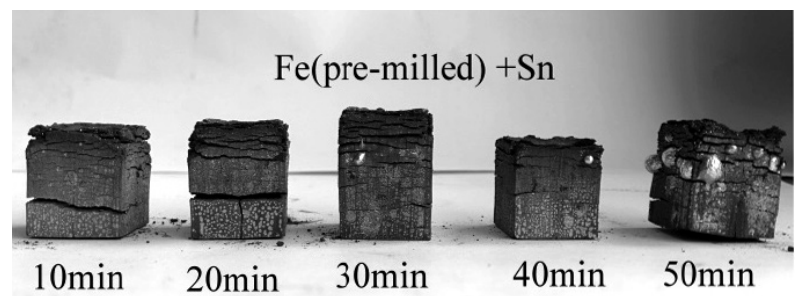

(b) Laminated cracks

Figure 4. Sintered specimens of mechanically alloyed Fe-Sn powder compacts produced via the second procedure. 
The sintered specimens of mechanically alloyed Fe-Sn powder compacts produced via the first procedure (Figures $3 \mathrm{a}$ and $3 \mathrm{~b}$ ) showed cracks in both the coin- and cube-shaped specimens, caused by volume changes of the different phases, (i.e., amounts of $\mathrm{Fe}, \mathrm{Sn}$, and $\mathrm{FeSn}_{2}$ with different unit cells changed after sintering), perpendicular to the pressing direction with high residual stress. In contrast, the sintered specimens of mechanically alloyed Fe-Sn powder compacts produced via the second mechanical alloying procedure (Figures $4 \mathrm{a}$ and $4 \mathrm{~b}$ ) showed no cracks in the coin-shaped specimens, but large cracks in the cube-shaped ones.

In addition to the external appearance of the sintered specimens, the formation of the $\mathrm{FeSn}_{2}$ intermetallic compound during liquid phase sintering was indicative of whether the two-step process could synthesize intermetallic compounds. The BSE images of the specimens of mechanically alloyed Fe-Sn powder compacts sintered at $600^{\circ} \mathrm{C}$ for different times are shown in Figure 5. The sintered specimens produced from the mechanically alloyed powder using the first procedure (Figure 5 series (a)) showed three different regions; the dark regions referred to the $\mathrm{Fe}$ phase, the light regions were the $\mathrm{Sn}$ phase, and the grey regions that formed at the $\mathrm{Fe} / \mathrm{Sn}$ interface represented the $\mathrm{FeSn}_{2}$ intermetallic compound phase. Relative XRD peak intensities of the $\mathrm{FeSn}_{2}$ intermetallic compound, compared to those of $\mathrm{Fe}$ and $\mathrm{Sn}$, increased with increasing sintering times. Elemental Fe and $\mathrm{Sn}$ were still observed in the microstructures of the sintered specimens. The XRD patterns in Figure 6 confirmed these results. As the sintering time increased, the Fe and $\mathrm{Sn}$ phases decreased slightly whereas the $\mathrm{FeSn}_{2}$ intermetallic compound content, indicated by its relative XRD peak intensity, increased. However, the presence of XRD peaks of both $\mathrm{Sn}$ and Fe phases suggested that the reaction between Fe and $\mathrm{Sn}$ was incomplete during liquid phase sintering of the mechanically alloyed powder produced via the first mechanical alloying procedure.

The sintered specimens produced from the mechanically alloyed powder using the second procedure (Figure 5 series (b)) showed no clear phase contrast. The microstructures showed grains, grain boundaries, and pores. The XRD patterns of this sintered material, as shown in Figure 7, also confirmed the BSE images in Figure 5 series (b). The FeSn 2 intermetallic compound contents increased with increasing sintering time, while the Fe and Sn phases drastically decreased and were likely to disappear. The pre-mechanically alloyed Fe powder aided the formation of the intermetallic compound. The pre-mechanically alloyed Fe powder particles were reduced to a very fine powder with large surface areas that not only facilitated the interfacial reaction to form intermetallic compounds, but also was the driving force that reduced the free energy of sintering. 

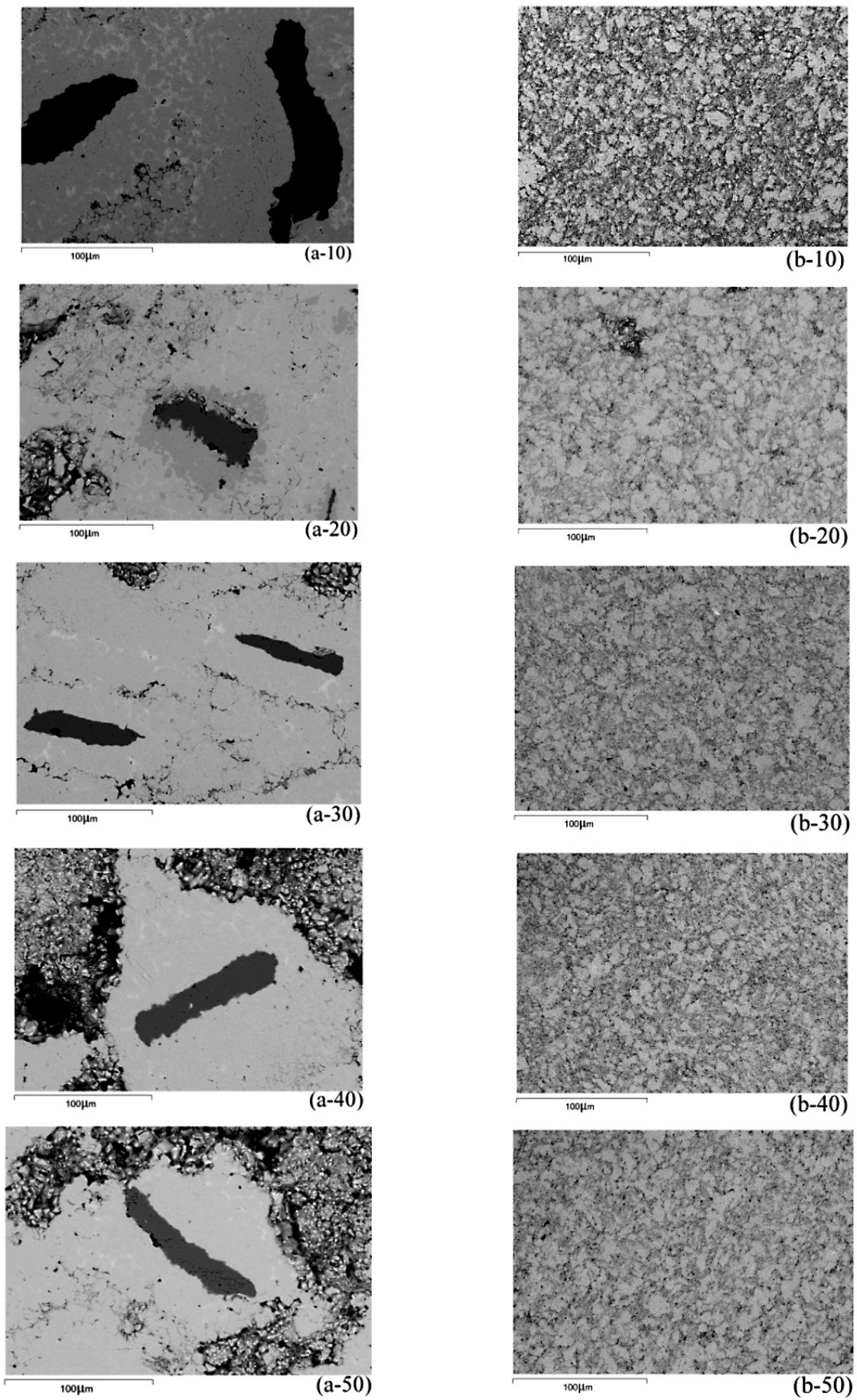

Figure 5. BSE images of the specimens of mechanically alloyed Fe-Sn powder compacts sintered at $600^{\circ} \mathrm{C}$ for different times; series (a) represents the powder produced via the first procedure, series (b) represents the powder produced via the second procedure. 


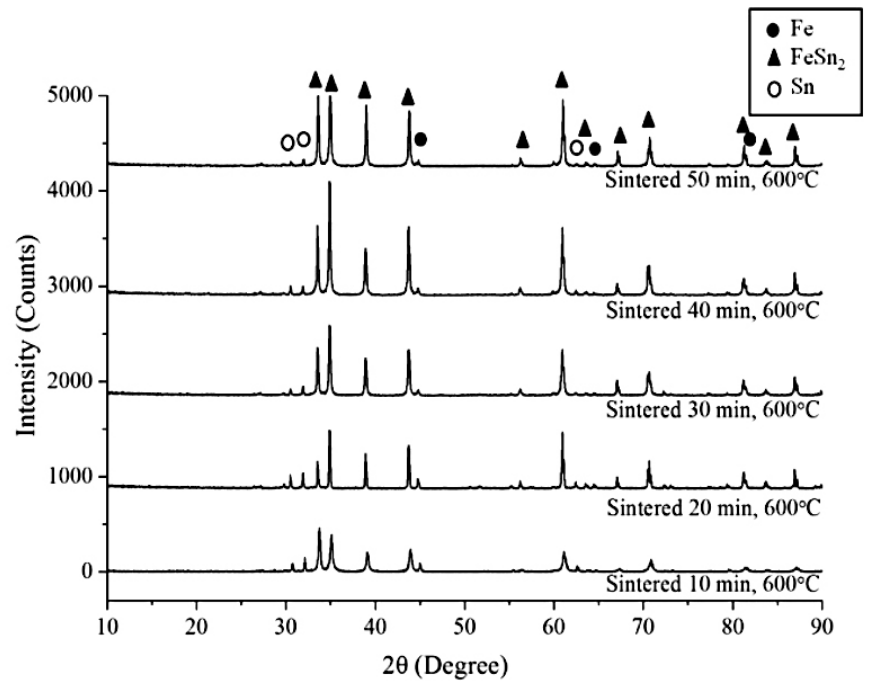

Figure 6. XRD patterns of the sintered specimens produced from the mechanically alloyed powder using the first procedure.

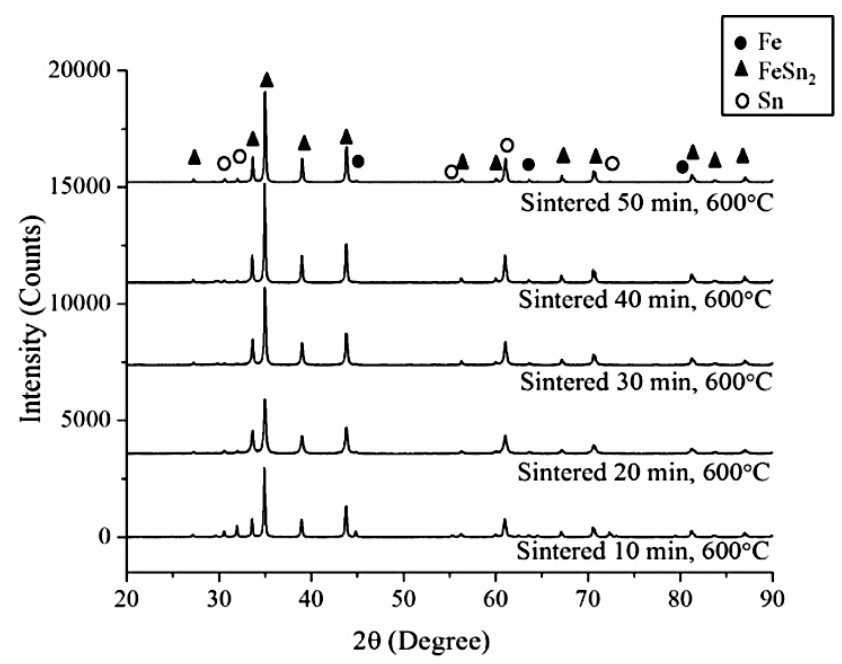

Figure 7. XRD patterns of the sintered specimens produced from the mechanically alloyed powder using the second procedure. 
Chemical analysis was performed on the Fe-Sn specimen produced via the first mechanical alloying procedure and sintered at $600^{\circ} \mathrm{C}$ for $50 \mathrm{~min}$. EDS line scanning across the area where a large Fe particle was enveloped with the Fe-Sn intermetallic compound showed that the Fe, Sn, and nitrogen $(\mathrm{N})$ concentrations changed abruptly at the interface of the Fe/ Fe-Sn intermetallic compound (Figure 8 ). The concentration profile of $\mathrm{N}$ resembled that of the Fe-Sn intermetallic compound, implying that $\mathrm{N}$ was adsorbed on the surface of the Fe-Sn intermetallic compound, but not on the Fe particle surface.
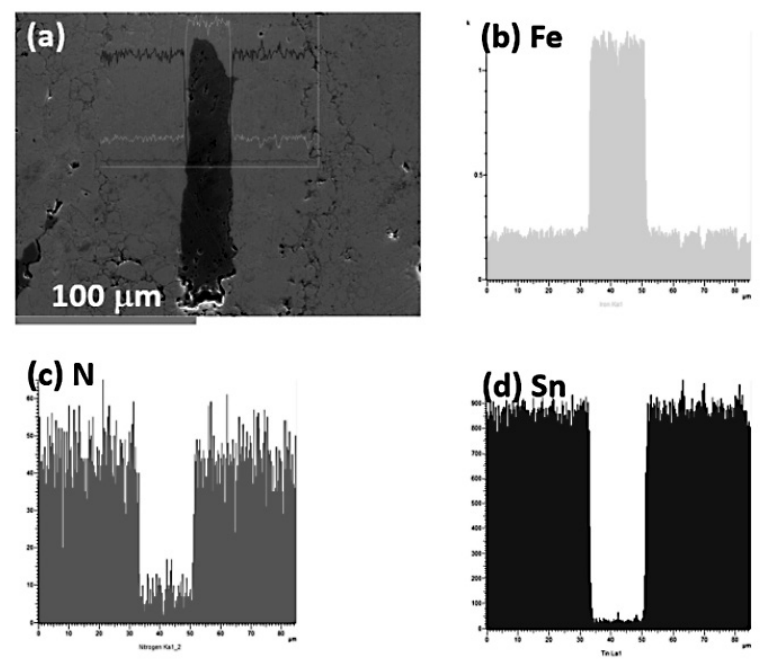

Figure 8. EDS line scanning of the Fe-Sn specimen produced via the first MA procedure and sintered at $600^{\circ} \mathrm{C}$ and for $50 \mathrm{~min}$.

\section{DISCUSSION}

\section{Effect of mechanical alloying}

In some catalytic applications, nanoparticles of bi-metals or intermetallics are needed due to their large active surface areas. Such nanoparticles can be produced by mechanical alloying (Pithakratanayothin et al., 2016). For electrochemical applications, the reactive solid components must not only have large surface areas, but also be porous to facilitate material transport. Sintering produces porous materials. Solid-state sintering of metal powders with particle sizes ranging from sub-micrometers to $200 \mu \mathrm{m}$ to form dense metals or alloys is a common practice in the powder metallurgical industry. The key phenomenon for sintered neck formation and alloying during solid-state sintering is diffusion of powder constituents or elemental atoms from bulk to contact areas between powder particles. In liquid phase sintering, the liquid phase forming powder melts and penetrates through boundaries between higher melting point powder particles and/or dissolves into higher melting point powder particles. The undissolved or remaining liquid phase solidifies during cooling to form a binder that bonds the higher melting 
point powder particles together. In most cases, interfacial interactions, including alloying and intermetallic compound formation, occur at the interface between the solid and liquid phases. Synthesis of the Fe-Sn intermetallic compound from $\mathrm{Fe}$ and $\mathrm{Sn}$ powders is thus based on a reaction that initiates at the interface and propagates throughout the whole powder compacts. The Fe/Sn interface generated by mechanical alloying facilitates the formation of an intermetallic compound, because it contains locations where the inter-diffusion of Sn and Fe occurs.

These interfacial intermetallic compounds may enhance wettability of liquid $\mathrm{Sn}$ on the solid Fe surface. Wettability prevents some of the liquid Sn from flowing out of the powder compacts or mechanically alloyed powder agglomerates. Enhancing the wettability of the interfacial intermetallic compound is commonly applied in soldering $\mathrm{Sn}$-base solders on $\mathrm{Cu}$ or $\mathrm{Ni}$ substrates (Huang and Lin, 2004; Zhang et al., 2011; Ho and Duh, 2013). However, a recent study on solder wettability of $\mathrm{Sn} / \mathrm{FeNi}$ plated on copper revealed that the wetting force was found to decrease slightly with the growth of a primary $\mathrm{FeSn}_{2}$ layer at the $\mathrm{Sn} / \mathrm{FeNi}$ interface (Chen at al., 2011). However, liquid phase sintering of the compacts of two as-received metal powders with large melting point differences, like the compacts of $\mathrm{Cu}+\mathrm{Sn}$ powders, results in liquid $\mathrm{Sn}$ flowing out of the sintered $\mathrm{Cu}$ compact without any evidence of $\mathrm{Cu} / \mathrm{Sn}$ interactions (Tongsri et al., 2016). In contrast, liquid phase sintering of mechanically alloyed $\mathrm{Cu}+\mathrm{Sn}$ powder compacts can successfully produce the $\mathrm{Cu}-\mathrm{Sn}$ intermetallic compound. Some research has reported synthesizing TM-Sn intermetallic compound using mechanical alloying followed by liquid phase sintering (Naille et al., 2007; Tongri and Tosangthum, 2011; Mahmoud et al., 2013; Meesa-ard et al, 2014; Tongsri et al., 2016). However, although the $\mathrm{FeSn}_{2}$ intermetallic compound could be synthesized from Fe-Sn powders produced via the first mechanical alloying procedure, incomplete reaction and some liquid Sn oozing were still observed (Meesa-ard et al, 2014). Liquid Sn oozing is undesirable; it causes problems related to incomplete reaction, compositional segregation, and distortion of the sintered part.

The large Fe powder particles have a small area of contact with the $\mathrm{Sn}$; in addition, mechanical alloying of the hard $(\mathrm{Fe})$ and soft $(\mathrm{Sn})$ powders deforms the soft Sn powder much more than the hard Fe powder. The soft Sn powder also buffers the Fe powder from the milling ball and thus large Fe powder particles remain in the mechanically alloyed Fe-Sn powder produced by the first mechanical alloying procedure.

To reduce Fe powder particle size and to increase mixing efficiency requires a new strategy; to investigate this, we compared two different mechanical alloying procedures. As shown in Figures 1 and 2, mechanical alloying of the as-received $\mathrm{Fe}$ and $\mathrm{Sn}$ powder mixtures (the first procedure) had a lower mixing efficiency than mechanical alloying of the pre-milled Fe and $\mathrm{Sn}$ powder mixtures (the second procedure). The first procedure did not produce a powder with homogeneous microstructures (Figure 1b), with large Fe powder particles with a small degree of deformation remaining, in contrast to the second procedure (Figure 1d). This lack of homogeneity in the first procedure was caused by the incomplete interaction between $\mathrm{Fe}$ and $\mathrm{Sn}$ during liquid phase sintering, as evidenced by Figures 
5a-10 to 5a-50 and Figure 8 . This was attributed to the slow interfacial reaction rate between solid $\mathrm{Fe}$ and liquid $\mathrm{Sn}$ at temperatures below $800^{\circ} \mathrm{C}$. According to (Kostrova and Lesnik, 1997), the spreading by diffusion of liquid $\mathrm{Sn}$ on the Fe surface only occurs at temperatures higher than $800^{\circ} \mathrm{C}$. This contrasts with other systems, like Co-Sn and Ni-Sn (Kostrova and Lesnik, 1997), in which the intermetallic compound layer at the interface can be formed by the mechanism of reactive diffusion at all temperatures during spreading.

The second mechanical alloying procedure effectively reduces the particle size of the Fe powder, because it is pre-milled before it is mechanically alloyed with the Sn powder.

\section{Size matters}

The chemical analysis using EDS line scanning (Figure 8) of the liquid-phase sintered Fe-Sn powder compact produced via the first mechanical alloying procedure showed a sharp interface between the large Fe powder particles and Fe-Sn intermetallic compounds in the form of a steep (near-vertical slope) chemical gradient. Constant Fe and Sn concentrations were observed in the area of the FeSn intermetallic compound surrounding the large Fe particles. This steep chemical gradient supported the aforementioned slow interfacial reaction rate between solid Fe and liquid $\mathrm{Sn}$ at temperatures below $800^{\circ} \mathrm{C}$, or with a slow dissolving process (Kostrova and Lesnik, 1997). In contrast, in the $\mathrm{Cu}-\mathrm{Sn}$ system produced via mechanical alloying and liquid phase sintering (Tongsri et al., 2016) and the $\mathrm{Cu}-\mathrm{Sn}$ solid state diffusion couple method (Yuan et al., 2016), the concentration gradient of $\mathrm{Cu}$ gradually decreased and $\mathrm{Sn}$ gradually increased from the $\mathrm{Cu}$ metal through theg $\mathrm{Cu} / \mathrm{Sn}$ interface to the $\mathrm{Cu}-\mathrm{Sn}$ intermetallic compound region and/or to Sn metal.

The sharp Fe/Fe-Sn intermetallic compound interface not only supported the slow interfacial reaction between solid $\mathrm{Fe}$ and liquid $\mathrm{Sn}$ at temperatures below $800^{\circ} \mathrm{C}$, but also related to particle size or dimension effect. The regions of the Sn-base material embedded with every fine Fe powder particle (appearing as white phases in Figure 1b) were converted to Fe-Sn intermetallic compound surrounding the large Fe particles (shown in Figure 8). This indicated that very fine $\mathrm{Fe}$ powder particles are required for the $\mathrm{Fe}$ and $\mathrm{Sn}$ particles to react during liquid phase sintering.

We tested the second mechanical alloying procedure to prove this hypothesis. In the second procedure, the as-received Fe powder was pre-milled, yielding very fine Fe powder. The pre-milled Fe powder was mixed with as-received Sn powder and mechanically alloyed, ensuring an efficient mix, as shown in Figures 1c, 1d, and $2 \mathrm{~b}$. The consequence of the improved mixing efficiency was evidenced by Figures 5b-10 to 5b-50 and 7. Trace XRD peaks of Fe and Sn and strong XRD peaks of $\mathrm{FeSn}_{2}$ indicated that the particle size of the reactant Fe powder was a crucial parameter of the reaction, i.e., the fine Fe particle size promoted formation of the Fe-Sn intermetallic compound during liquid phase sintering.

In the physical phenomenon of sintering (Exner and Arzt, 1996) and the formation of intermetallic compounds via liquid phase sintering (Tongsri et al., 
2016) and solid state diffusion coupled method (Yuan et al., 2016), diffusion of the reactant elements is of paramount importance. Diffusion is inversely related to material crystallite size (Jiang et al., 2004). In nanocrystalline materials, characterized by a microstructural length scale of 1 to $100 \mathrm{~nm}$ (Liu et al., 2012), the numerous interfaces provide a high density of short circuit diffusion paths. Thus, nanocrystalline materials are expected to exhibit an enhanced self and solute diffusivity (Gleiter, 1989). Several researchers have experimentally proven that nanocrystalline systems have anomalously high diffusivity (Gleiter, 1992; Das et al., 1999; Chattopadhyay et al., 2001). The root cause of enhanced diffusion by mechanical alloying is the increase in density defects (e.g., dislocations and vacancies) (Bhattacharya and Arzt, 1993; Khina and Lovshenko, 2011).

Based on our experimental results, a complete reaction between Fe and $\mathrm{Sn}$ powders can be obtained when both powders have fine particle sizes and good mixing efficiency, as in our second mechanical alloying procedure

\section{ACKNOWLEDGEMENTS}

The authors (Nattaya Tosangthum and Ruangdaj Tongsri) are grateful for financial support from the National Metal and Materials Technology Center (MTEC), Pathum Thani, Thailand, under the project MT-B-58-MET-07-269-I. The author (Pinya Meesa-Ard) is grateful for technical support from the Powder Metallurgy Research and Development Unit (PM_RDU) of Thailand National Metal and Materials Technology Center (MTEC), Pathum Thani, Thailand and financial support from Thailand Advanced Institute of Science and Technology (TAIST Tokyo Tech, KMUTT, and NSTDA). The authors would like to thank Ussadawut Patakham of MTEC for his help with chemical analysis using EDS line scanning.

\section{REFERENCES}

Bhattacharya, A.K., and Arzt, E. 1993. Plastic deformation and its influence on diffusion process during mechanical alloying. Scripta Metallurgica. 28: 395-400. https://doi.org/10.1016/0956-716X(93)90072-Z

Chamas, M., Lippens, P.E., Jumas, J.C., Hassoun, J., Panero, S., and Scrosat, B. 2011. Electrochemical impedance characterization of $\mathrm{FeSn}_{2}$ electrodes for Li-ion batteries. Electrochimica Acta. 56: 6732-6736. https://doi. org/10.1016/j.electacta.2011.05.069

Chattopadhyay, P.P., Pabi, S.K., and Manna, I. 2001. On the enhancement of diffusion kinetics in nanocrystalline materials. Materials Chemistry and Physics. 68: 80-84. https://doi.org/10.1016/S0254-0584(00)00282-0

Chen, C., Zhang, L., Lai, Q., Li, C., and Shang, J.K. 2011. Evolution of solder wettability with growth of interfacial compounds on tinned FeNi plating. Journal of Materials Science: Materials in Electronics. 22: 1234-1238. https://doi.org/10.1007/s10854-011-0292-2 
Chen, J. 2013. Review Recent Progress in Advanced Materials for Lithium Ion Batteries. Materials. 6: 156-183. https://doi.org/10.3390/ma6010156

Das, D., Chatterjee, P.P., Manna, I., and Pabi, S.K. 1999. A measure of enhanced diffusion kinetics in mechanical alloying of $\mathrm{Cu}-18$ at.\% Al by planetary ball milling. Scripta Materialia. 41: 861-866.

Exner, H.E., and Arzt, E. 1996. Sintering processes. In: Physical metallurgy (Cahn, R.W. and Haasen, P.; eds.). Elsevier Science, Netherlands, 2627-2662.

Gleiter, H. 1989. Nanocrystalline materials. Progress in Materials Science. 33: 223-315. https://doi.org/10.1016/0079-6425(89)90001-7

Gleiter, H. 1992. Diffusion in nanostructured metals, Physica status solidi (b). 172: 41-51. https://doi.org/10.1002/pssb.2221720106

Ho, C.Y., and Duh, J.G. 2013. Wetting kinetics and wettability enhancement of Pd added electrolytic Ni surface with molten $\mathrm{Sn}-3.0 \mathrm{Ag}-0.5 \mathrm{Cu}$ solder. Materials Letters. 92: 278-280. https://doi.org/10.1016/j.matlet.2012.10.063

Huang, C.W., and Lin, K.L. 2004. Wetting Properties of and Interfacial Reactions in Lead-free $\mathrm{Sn}-\mathrm{Zn}$ Based Solders on $\mathrm{Cu}$ and $\mathrm{Cu}$ Plated with an Electroless Ni-P/Au Layer. Materials Transactions. 45: 588-594. http://doi.org/10.2320/ matertrans.45.588

Hubertus, G., and Malcolm, N. 2006. Equations of state of several iron-tin intermetallic compound compounds. Journal of Physics and Chemistry of Solids. 67: 2027-2032. https://doi.org/10.1016/j.jpcs.2006.05.056

Jiang, Q., Zhang, S.H., and Li, J.C. 2004. Grain size-dependent diffusion activation energy in nanomaterials. Solid State Communications. 130: 581-584. https://doi.org/10.1016/j.ssc.2004.03.033

Khina, B.B., and Lovshenko, G.F. 2011. Modeling Enhanced Diffusion Mass Transfer in Metals during Mechanical Alloying, Mass Transfer in Multiphase Systems and its Applications, Prof. Mohamed El-Amin (Ed.). ISBN978-953-307-215-9, InTech. Available from: http://www.intechopen. com/books/mass-transfer-inmultiphase-systems-and-its-applications/modeling-enhanced-diffusion-mass-transfer-in-metals-duringmechanical-alloying. https://doi.org/10.5772/14152

Koch, C.C., and Whittenberger, J.D. 1996. Mechanical milling/alloying of intermetallic compounds. Intermetallics. 4: 339-355. https://doi.org/10.1016/09669795(96)00001-5

Kostrova, L.I., and Lesnik, N.D. 1997. Chemical interaction at the initial stage of spreading, in Interfacial Science in Ceramic Joining (Bellosi A., Kosmac T., Tomsia A.P., eds.). Springer Science+Business Media, Slovenia. 69-77. Lee, J.M., Chang, W.S., Yu, B.C., Kim, H., Im, D.M., Doo, S.K., and Sohn, H.J., 2010. Enhancement of cyclability using recombination reaction of $\mathrm{Cu}$ for $\mathrm{Sn}_{2} \mathrm{Fe}$ nanocomposite anode for lithium-ion batteries. Electrochemistry Communications. 12: 928-932. https://doi.org/10.1016/j.elecom.2010.04.023

Liu, J., Cui, H., Zhou, X., and Zhang J. 2012. Microstructure characterization and thermal stability of nanocrystalline $\mathrm{Cu}$ powders processed via cryomilling. Materials Transactions. 53: 766-769. http://doi.org/10.2320/matertrans. M2011374 
Mahmoud, A., Chamas, M., Jumas, J.C., Phillipe, B., Dedryvere, R., Gonbeau, D., Saadoune, I., and Lippens P.E. 2013. Electrochemical performances and mechanisms of $\mathrm{MnSn}_{2}$ as anode material for Li-ion batteries. Journal of Power Sources. 24: 246-251. https://doi.org/10.1016/j.jpowsour.2013.01.110

Mao, O., and Dahn, J.R. 1999. Mechanically Alloyed Sn-Fe (-C) Powders as Anode Materials for Li-Ion Batteries: 11l. $\mathrm{Sn}_{2} \mathrm{Fe}: \mathrm{SnFe}_{3} \mathrm{C}$ Active/lnactive Composites. Journal of The Electrochemical Society. 146: 414-422. https:// doi.org/10.1149/1.1391624

Meesa-ard, P., Uthaisangsuk, V., Tosangthum, N., and Tongsri, R. 2014. FeSn 2 Intermetallic compound for EV battery anode produced by mechanical alloying and liquid phase sintering. SAE Technical Paper 2014-01-2009. https://doi.org/10.4271/2014-01-2009.

Morakotjinda, M., Fakpan, K., Yotkaew, T., Tosangthum, N., Krataithong, R., Daraphan, A., Siriphol, P., Wila, P., Vetayanugul, B., and Tongsri R. 2010. Gas atomization of low melting-point metal powders. Chiang Mai Journal of Science. 37: 55-63.

Naille, S., Ionica-Bousquet, C.M., Robert, F., Morato, F., Lippens, P.E., and Olivier-Fourcade, J. 2007. Sn-based intermetallic compound materials Performances and mechanisms. Journal of Power Sources. 174: 10911094. https://doi.org/10.1016/jpowersour.2007.06.040

Paul, S., Eckhard, K., Paul, B., James, C., Evan, S., and Daniel, K. 2005. Requirements for future automotive batteries - a snapshot. Journal of Power Sources. 144: 505-512. https://doi.org/10.1016/j.jpowsour.2004.11.007

Pithakratanayothin, S., Tongsri, R., Chaisuwan, T., and Wongkasemjit, S. 2016. A simple route to $\mathrm{Cu}_{\mathrm{x}} \mathrm{Sn}_{(100-\mathrm{x})}$ intermetallic nanoparticle catalyst for ultra-phenol hydroxylation. Materials Chemistry and Physics. 181: 452-461. https://doi.org/10.1016/j.matchemphys.2016.06.081

Richter, G., and Eberhard, M. 2005. The challenge to the automotive battery industry: the battery has to become an increasingly integrated component within the vehicle electric power system. Journal of Power Sources. 144: 438-460. https://doi.org/10.1016/j.jpowsour.2004.10.031

Tongsri, R., and Tosangthum, N. 2011. Solid state transformation of non-equilibrium, Ni-Sn powder with a eutectic composition. Songklanakarin Journal of Science and Technology. 33: 209-214.

Tongsri, R., Tosangthum, N., Yotkaew, T., Muthitamongkol, P., Sri-on, A., and Patakham, U. 2016. Characterization of liquid-phase sintered materials produced from mechanically alloyed $\mathrm{Cu}+\mathrm{Sn}$ powder. Materials Charaterization. 113: 52-59. https://doi.org/10.1016/j.matchar.2016.01.001

Wang, X.L., Feygenson, M., Chen, H., Lin, C.H., Ku, W., Bai, J., Meigan, C.A., Trevor, A.T., and Han, W.Q. 2011. Nanospheres of a New Intermetallic compound $\mathrm{FeSn}_{5}$ Phase: Synthesis, Magnetic Properties and Anode Performance in Li-ion Batteries. Journal of the American Chemical Society. 133: 11213-11219. https://doi.org/10.1021/ja202243j 
Yuan, Y., Guan, Y., Li, D., and Moelans, N. 2016. Investigation of diffusion behavior in $\mathrm{Cu}-\mathrm{Sn}$ solid state diffusion couples. Journal of Alloys and Compounds. 661: 282-293. https://doi.org/10.1016/j.jallcom.2015.11.214

Zhang, C.Q., Tu, J.P., Huang, X.H., Yuan, Y.F., Wang, S.F., and Mao, F. 2008. Preparation and electrochemical performances of nanoscale $\mathrm{FeSn}_{2}$ as anode material for lithium ion batteries. Journal of Alloys and Compounds. 457: 81-85. https://doi.org/10.1016/j.jallcom.2007.03.039

Zhang, L., Xue, S.B., Gao, L.L., Sheng, Z., Dai, W., Ji, F., Ye, H., Chen, Y., and Yu, S.L. 2011. Effects of bulk $\mathrm{Cu}_{6} \mathrm{Sn}_{5}$ intermetallic compound compounds on the properties of Sn-Ag-Cu-Ce soldered joints. Journal of Soldering and Surface Mount Technology. 23: 4-9. https://doi.org/10.1108/09540911111099460 
none 